\title{
Strategy for Designing Self-Assembling Peptides to Prepare Transparent Nanofiber Hydrogel at Neutral pH
}

\author{
Hidenori Yokoi ${ }^{1}$ and Takatoshi Kinoshita ${ }^{2}$ \\ ${ }^{1} \mathrm{R}$ \& D Division, Applied Technology Development Department, Menicon Co., Ltd., 5-1-10 Takamoridai, \\ Kasugai, Aichi 487-0032, Japan \\ ${ }^{2}$ Department of Frontier Materials, Graduate School of Engineering, Nagoya Institute of Technology, Gokiso-cho, \\ Showa-ku, Nagoya 466-8555, Japan \\ Correspondence should be addressed to Hidenori Yokoi, h-yokoi@menicon-net.co.jp \\ Received 16 December 2011; Revised 6 March 2012; Accepted 7 March 2012 \\ Academic Editor: Tong Lin
}

Copyright (C) 2012 H. Yokoi and T. Kinoshita. This is an open access article distributed under the Creative Commons Attribution License, which permits unrestricted use, distribution, and reproduction in any medium, provided the original work is properly cited.

\begin{abstract}
This study examined the formation of nanofiber hydrogels at neutral $\mathrm{pH}$ for 16 types of peptides with different net charges, hydrophobicities, and degrees of polymerization. The peptides formed various hydrogels depending on the arrangement of charged amino acids in the antiparallel $\beta$-sheet structure. Circular dichroism (CD) measurement, atomic force microscopy (AFM), visible light spectroscopy, and dynamic viscoelasticity measurement showed that the formation of transparent nanofiber hydrogels in peptides requires at least 2 additional positively or negatively charged amino acids per peptide. When designing the amino acid sequence, it is important to consider both the net charge and position of the charged amino acids, and it should be ensured that basic amino acids do not face other basic ones in the antiparallel $\beta$-sheet structure. Peptides that had charged amino acids clustered at the center of the nanofiber formed rigid gels.
\end{abstract}

\section{Introduction}

Molecular self-assembly [1-10] is a useful approach for fabricating nanofibers. In this process, molecules, once designed, are dissolved in a solvent, following which they proceed to self-assemble into nanofibers without any equipment or complicated procedures being required. A key point in this process is the positioning of functional groups in the molecule; this is important from the viewpoint of enabling suitable interactions among molecules, such as electrostatic interaction, hydrophobic interaction, and hydrogen bonding. Therefore, molecules need to be designed skillfully, and advanced techniques are required for their synthesis. Peptides are commonly used as a building block to design self-assembling molecules. Peptides are synthesized by combining two or more amino acids from among the 20 naturally occurring ones. Peptides form well-defined secondary structures, such as an $\alpha$-helix or $\beta$-sheet, and therefore, they are used as nanoscale building blocks to construct well-defined structures. In addition, peptides can be modified to exhibit novel functionalities, such as cell adhesion or antimicrobial ability, simply by changing the sequence of their constituent amino acids. Furthermore, because peptides are biocompatible and biodegradable, they hold great promise for medical applications. One of the advantages of using peptides is that methods have already been established for their synthesis [11]. In fact, an automatic peptide synthesizer based on the solid-phase peptide synthesis method is commercially available. A desired peptide can also be obtained from custom peptide suppliers.

Thus far, various self-assembling peptide nanofibers have been investigated [12-23]. Zhang et al.'s pioneering study [24] focused on a part of the amino acid sequence of Zuotin, a Z-DNA binding protein in yeast [25], and they synthesized various peptides that have alternating charged and uncharged amino acids-for example, the 16-residue peptide RADA16 $\left(\mathrm{CH}_{3} \mathrm{CO}-\mathrm{RADARADARADARADA}-\mathrm{NH}_{2}\right)$ that consists of hydrophobic alanine (Ala, A), negatively charged aspartic acids (Asp, D), and positively charged arginine (Arg, R). In this peptide, an equal number of acidic and 
basic amino acids were arranged in a regular pattern. They discovered that this peptide self-assembled into nanofibers that had a $\beta$-sheet structure through weak interactions such as electrostatic interaction, hydrogen bonding, van der Waals force, and hydrophobic interaction. The nanofibers were physically cross-linked through the electrostatic interaction among them to form a three-dimensional (3D) network. This self-assembly yielded a peptide aqueous solution gel with water content of $99.5 \mathrm{wt} \%$. The 3D network of peptide nanofibers was easily broken into smaller fragments by mechanical stimuli, such as stirring or sonication. However, these fragments quickly reassembled into a nanofiber scaffold that was indistinguishable from the original material [26]. This nonanimal-derived material can potentially be used as an injectable drug delivery system (DDS) device [27, 28], an instant hemostat [29], and a cell culture scaffold [30, 31].

Various aspects of peptide self-assembly, such as the hydrophobicity of amino acids $[32,33]$, electrostatic interaction [34, 35], temperature [36], and ion strength [37], have been investigated previously. In this study, we aim to derive the parameters necessary to form a gel with high transparency at neutral $\mathrm{pH}$ by customizing Zhang's peptide, which has a regular sequence of amino acids and various types of applicable amino acids. Zhang's peptide is not completely transparent, making it unsuitable for applications in the optical and ophthalmological fields; it does, however, have sufficient transparency for observing cultured cells in a gel. Some previous reports [38-42] have described peptides that form a transparent nanofiber hydrogel at neutral $\mathrm{pH}$. However, these reports cover few examples, and they do not elaborate on the design strategy in adequate detail. To realize the widespread use of self-assembling peptides, they must be easily customizable to be applicable to various applications. As such, a guiding principle for designing self-assembling peptides would be most beneficial. Herein, we investigate the design of peptides that form a transparent hydrogel at neutral $\mathrm{pH}$ by characterizing various peptides with different net charge, degree of polymerization, and hydrophobicity.

\section{Materials and Methods}

2.1. Peptide. All the peptides in this study were manually synthesized by the standard solid-phase method, using 9-fluorenylmethoxycarbonyl (Fmoc) chemistry. In this synthesis, $400 \mathrm{mg}$ of 4-(2,4-Dimethoxyphenyl-Fmoc-aminomethyl) phenoxyacetyl-norleucyl-cross-linked ethoxylate acrylate resin (Peptides Institute Inc.) was placed in a flask of solid organic synthesizer CCS-150 M (EYELA). To the activated group of resin, three equivalents of Fmoc -protected amino acid, 1-hydroxybenzotriazole hydrate $\left(\mathrm{HOBt} \cdot \mathrm{H}_{2} \mathrm{O}\right)$ or 1-hydroxy-7-azabenzotriazole (HOAt), and $\mathrm{N}, \mathrm{N}^{\prime}$-diisopropylcarbodiimide (DIPCI) as a coupling reagent, were dissolved in $5 \mathrm{~mL}$ of dimethylformamide (DMF) and stirred for $2 \mathrm{~h}$. Deprotection of the Fmoc group was carried out by stirring the resin in a $20 \%$ piperidine in DMF. Amino acids were polymerized by repeating this process. To protect the N-terminal of the peptide with an acetyl group, 10 molar equivalents of acetic anhydride was reacted for $2 \mathrm{~h}$ in $5 \mathrm{~mL}$ of DMF. After washing the resin with dichloromethane, it was dried. To cleave the peptide from the resin, it was treated in a cleavage cocktail of trifluoroacetic acids (TFAs), 1,2-ethanedithiol, thioanisole, and water-mixed solution $(17: 1.7: 1: 1$ in volume fraction) or TFA, triisopropylsilane (TIPS), and water-mixed solution (38:1:1 in volume fraction) for $3 \mathrm{~h}$. At this time, the Cterminal of the peptide was amidated, that is, both the $\mathrm{N}$ and C-termini remained uncharged. After filtration of the solution, the peptide was precipitated by adding an excess amount of cold diethylether. After repeatedly stirring the peptide in diethylether and removing the supernatant by centrifuging $(3500 \mathrm{rpm}, 10 \mathrm{~min})$, the peptide was vacuum dried. After dissolving the peptide in Milli-Q water, the solution was filtered using a filtration paper (Advantec) and then freeze-dried. Further purification was not performed. The molecular weight of these crude peptides was measured by matrix-assisted laser desorption/ionization timeof-flight mass spectroscopy (MALDI-TOF-MS) (Voyager RN BioSpectrometry Workstation, Perceptive Biosystems Co., Ltd.).

A peptide aqueous solution of $0.5 \mathrm{wt} \%$ was prepared by adding peptide powder in a $0.1 \mathrm{M}$ Tris- $\mathrm{HCl}$ buffer $(\mathrm{pH} 7.5)$ and sonicating for $30 \mathrm{~s}$ using a homogenizer.

2.2. Circular Dichroism Spectroscopy. A secondary structure of peptide in an aqueous solution was evaluated by CD spectroscopy. An aqueous solution with a concentration of ca. $3 \times 10^{-3} \mathrm{M}$ was prepared by diluting the $0.5 \%(\mathrm{w} / \mathrm{v})$ stock solution with Tris- $\mathrm{HCl}$ buffer. When it was difficult to dissolve the peptide in water at neutral $\mathrm{pH}$, it was first dissolved in water at an acidic $\mathrm{pH}$, and then the $\mathrm{pH}$ was adjusted to neutral by adding Tris- $\mathrm{HCl}$ buffer. A quartz cuvette with a $0.5 \mathrm{~mm}$ path length was used for measurement. The molar ellipticity from 195 to $260 \mathrm{~nm}$ was measured with a CD spectrometer, J-820 K Spectropolarimeter (JASCO), at room temperature.

2.3. Atomic Force Microscopy. The morphology of peptide assemblies was observed with an atomic force microscope (AFM). First, peptides were dissolved in $0.1 \mathrm{M}$ Tris- $\mathrm{HCl}$ buffer at a concentration of $0.5 \mathrm{w} / \mathrm{v} \%$. The $\mathrm{pH}$ of the peptide solution was around 7 . Then, the solution was diluted 20fold using $0.1 \mathrm{M}$ Tris- $\mathrm{HCl}$ buffer, which adjusted the $\mathrm{pH}$ to 7.5 , and $1 \mu \mathrm{l}$ of the solution was placed on a mica substrate. After a couple of seconds, to remove excess peptide, the mica substrate was rinsed by dropping $100 \mu \mathrm{l}$ of Milli-Q water gradually onto it and air-drying it. The surface of the mica substrate was observed with a Nano ScopeIIIa (Digital Instruments) AFM operated in Tapping mode at room temperature. An NCH-10 silicon nitride tip (NanoDevice) was used for Tapping Mode. The cantilever length was $125 \mu \mathrm{m}$, and the tip radius was ca. $5 \mathrm{~nm}$.

2.4. Visible Light Spectroscopy. The transparency of the peptide gel was measured using a V-550UV/VIS spectrometer (JASCO). The peptide solution of $0.5 \mathrm{wt} \%(0.1 \mathrm{M}$ Tris$\mathrm{HCl}, \mathrm{pH} \sim 7)$ was placed in a glass cuvette with a $10 \mathrm{~mm}$ 


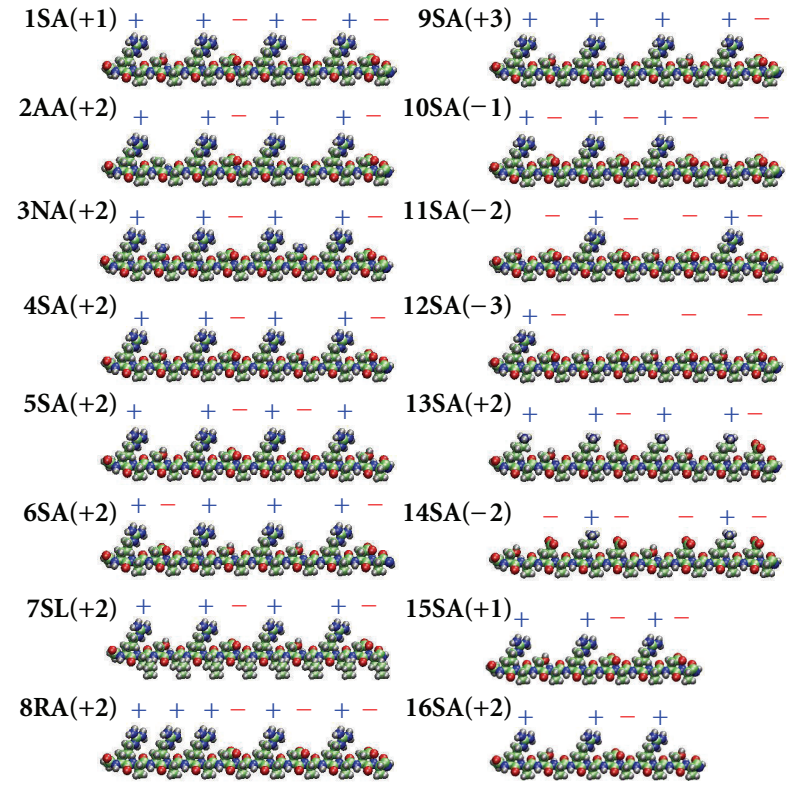

Figure 1: Molecular model of peptides (Carbon atoms: green, oxygen atoms: red, nitrogen atoms: blue, and hydrogen atoms: white).

path length, and a transparency from 380 to $780 \mathrm{~nm}$ was measured.

2.5. Dynamic Viscoelasticity Measurement. The viscoelastic property of the peptide solution was measured using an AR1000 (TA Instruments) rotational rheometer by the parallel plate method with $600 \mu \mathrm{m}$ gap distance. For this, $750 \mu \mathrm{L}$ of peptide solution was placed on the lower plate, and a $40 \mathrm{~mm}$-diameter parallel steel plate was used as the upper plate. The upper plate was covered by a solvent trap to prevent solvent evaporation. A frequency sweep measurement was performed from 0.1 to $100 \mathrm{rad} / \mathrm{s}$. The temperature of the lower plate was $25^{\circ} \mathrm{C}$, and $1 \mu \mathrm{N} \cdot \mathrm{m}$ of torque was applied.

\section{Results and Discussion}

3.1. Design of Peptides and Their Molecular Models. In this study, we designed sixteen types of peptides with different net charge, degree of polymerization, and hydrophobicity. The amino acid sequence of RADA16, the starting material used to design peptides in this study, and those of the designed peptides are listed in Figure 10 . Molecular models of the peptides were built using Biomer ver. 1.0 alpha [43] and visualized using VMD [44] (Figure 1). The net charge of the peptide molecules at pH 7.0 is listed in Figure 10. The number of acidic and basic amino acids in the peptide molecule was changed by substituting some of the acidic amino acids of RADA16 with basic ones or by substituting a charged amino acid with an uncharged one. We avoided substituting the charged amino acid with a bulky one in consideration of its tendency [45] to form an $\alpha$-helix.

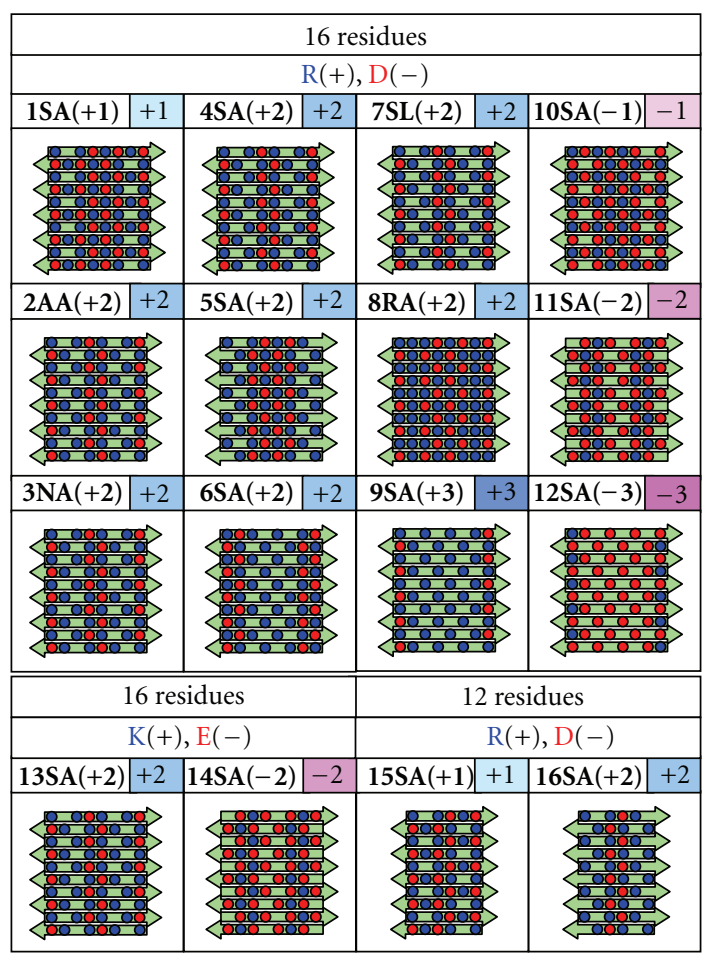

FIgURE 2: Schematic illustrations of the hydrophilic surface of the antiparallel $\beta$-sheet structure (red circle: acidic amino acid, blue circle: basic amino acid). Each $\beta$-sheet structure has AABA lanes perpendicular to the molecular axis, and each has its own pattern of charged amino acids.

When a peptide with alternating hydrophilic and hydrophobic amino acids forms an antiparallel $\beta$-sheet structure, the corresponding amino acid residues are located on opposite sides. It was assumed that each peptide formed an antiparallel $\beta$-sheet structure. Figure 2 shows schematic illustrations of the hydrophilic surface. In all peptides except 8RA(+2), the amino acids were arranged such that basic (acidic) amino acids did not face other basic (acidic) ones in the antiparallel $\beta$-sheet structure; this prevented electrostatic repulsion in the antiparallel $\beta$-sheet structure, in turn preventing self-assembly from being disturbed. A lane was formed in which acidic and basic amino acids were lined up alternately, vertical to the peptide main chain axis in the $\beta$-sheet structure. This lane of charged amino acids, called the alternating acidic and basic amino acid (AABA) lane in this study, causes electrostatic attraction. Each peptide has a different number and position of AABA lanes.

3.2. Secondary Structure of Peptides. The secondary structure of peptides was investigated by circular dichroism (CD) spectroscopy to examine how the changes in the net charge, degree of polymerization, and hydrophobicity of a peptide affect its $\beta$-sheet formation (Figure 3 ). The negative peak at around $215 \mathrm{~nm}$ is attributed to the $\beta$-sheet structure of peptides, with the peak intensity being dependent on the $\beta$ sheet content in the secondary structure of peptides [46]. 


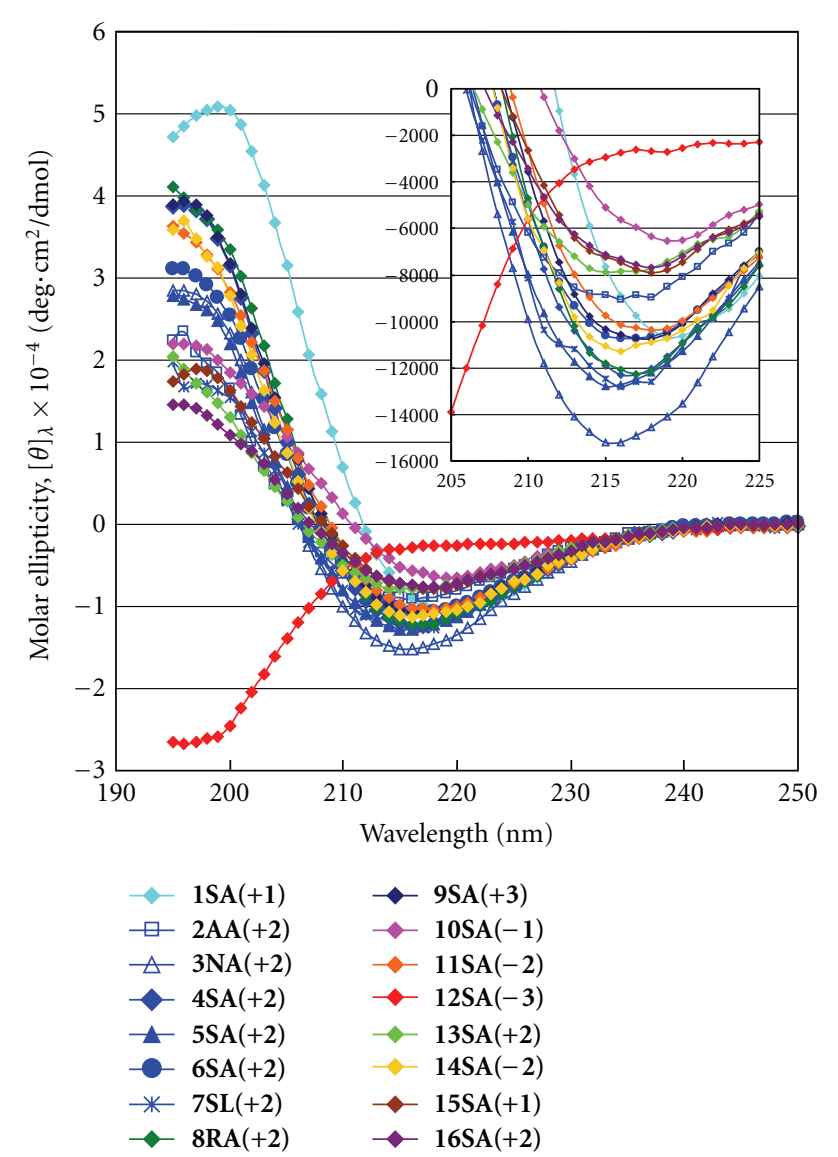

Figure 3: CD spectra of peptides. The peptide concentration is ca. $3 \times 10^{-3} \mathrm{M}$ in $0.1 \mathrm{M}$ Tris- $\mathrm{HCl}$ buffer $(\mathrm{pH} 7.5)$. The minimum molar ellipticity at $215 \mathrm{~nm}$ is based on the $\beta$-sheet structure of the peptide.

1SA $(+1)$ and $10 \mathrm{SA}(-1)$ were poorly soluble in aqueous solutions at neutral $\mathrm{pH}$; therefore, their solutions for $\mathrm{CD}$ measurement were first prepared at an acidic $\mathrm{pH}$ and then adjusted to neutral. Their CD spectra showed a minimum value at $218 \mathrm{~nm}$, which is slightly redshifted compared with the other spectra. This might be caused by both peptides forming aggregates in an aqueous solution.

Spectra based on the $\beta$-sheet structure were observed for all peptides except for $12 \mathrm{SA}(-3)$. The molar ellipticity of each peptide at $215 \mathrm{~nm}$ is shown in Figure 4.

Between $4 \mathrm{SA}(+2)$ and $9 \mathrm{SA}(+3)$, the former was found to have higher $\beta$-sheet content. This result is related to the number of AABA lanes, that is, the strong electrostatic interaction among peptide molecules led to the formation of the $\beta$-sheet structure.

Negatively charged peptides 11SA $(-2)$ and 12SA(-3) showed slightly different behavior. The former formed a $\beta$ sheet structure, whereas the latter did not. The molecular model of the latter suggests that it might fold via intramolecular interaction among Arg residues at the N-terminal of the peptide and Asp residues near the C-terminal.

Interestingly, 15SA(+1) and $16 \mathrm{SA}(+2)$ had comparable molar ellipticities, although the former has more AABA lanes than does the latter. The poor solubility of the former

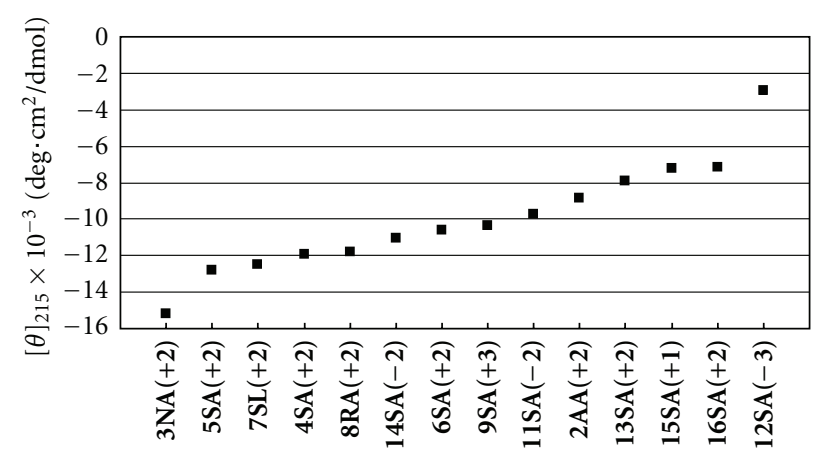

FIgure 4: Molar ellipticity of peptides at $215 \mathrm{~nm}$ in the CD spectra.

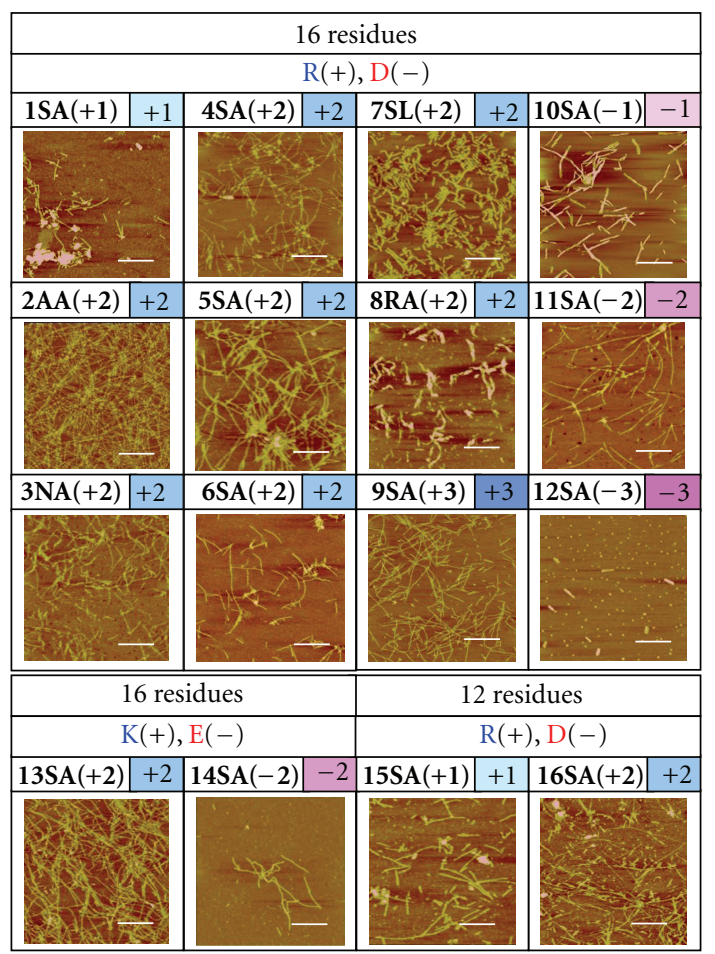

FIGURE 5: AFM images of peptide assembly on a mica substrate in air. Scale bar: $500 \mathrm{~nm}$.

suggests that aggregation may have decreased from its peak intensity.

$4 \mathrm{SA}(+2), 5 \mathrm{SA}(+2)$, and $6 \mathrm{SA}(+2)$ differ only in terms of the position of the AABA lane (with those of $5 \mathrm{SA}(+2)$ being located at the center of the nanofibers), and the $\beta$-sheet content decreases in the following order: $5 \mathrm{SA}(+2)>4 \mathrm{SA}(+2)$ $>$ 6SA $(+2)$.

Among $2 \mathrm{AA}(+2), 3 \mathrm{NA}(+2)$, and $4 \mathrm{SA}(+2)$, the $\beta$-sheet content decreases in the following order: $3 \mathrm{NA}(+2)>$ $4 \mathrm{SA}(+2)>2 \mathrm{AA}(+2)$. This might be attributable to hydrogen bonds among the $-\mathrm{CONH}_{2}$ group of asparagine (Asn) residues and the Arg residues. The sequence of alternating hydrophilic and hydrophobic amino acids has a high tendency to form a $\beta$-sheet structure. However, it is not necessary to arrange hydrophilic and hydrophobic amino acids alternately to form the $\beta$-sheet structure. 


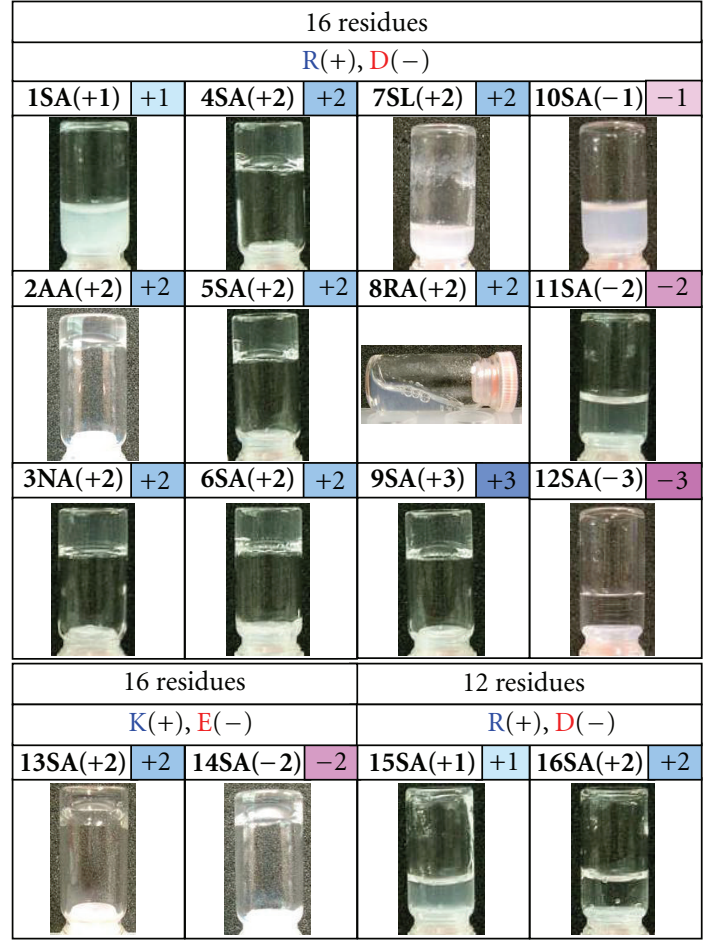

FIGURE 6: Appearance of the peptide aqueous solution. The peptide concentration is $0.5 \mathrm{wt} / \mathrm{v} \%$ in $0.1 \mathrm{M}$ Tris- $\mathrm{HCl}$ buffer ( $\mathrm{pH} 7.5$ ).

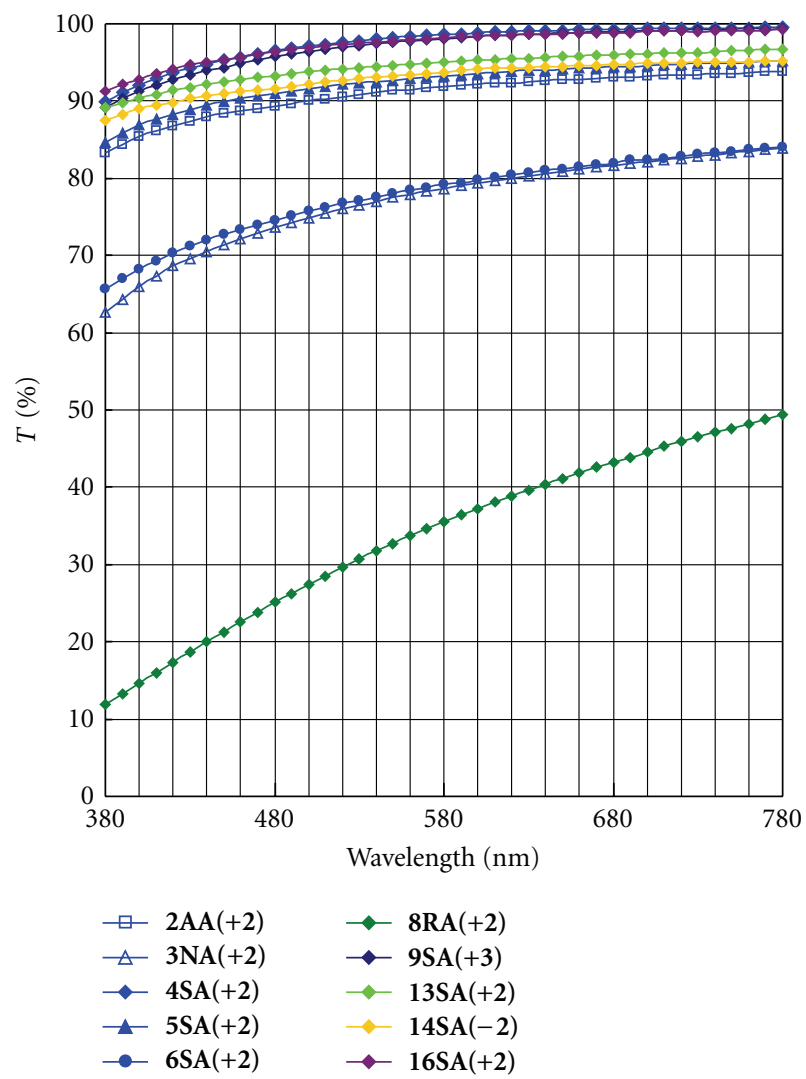

Figure 7: Visible light spectra of peptide hydrogels. The peptide concentration is $0.5 \mathrm{wt} / \mathrm{v} \%$ in $0.1 \mathrm{M}$ Tris- $\mathrm{HCl}$ buffer ( $\mathrm{pH}$ 7.5). Path length of the glass cuvette is $10 \mathrm{~mm}$.

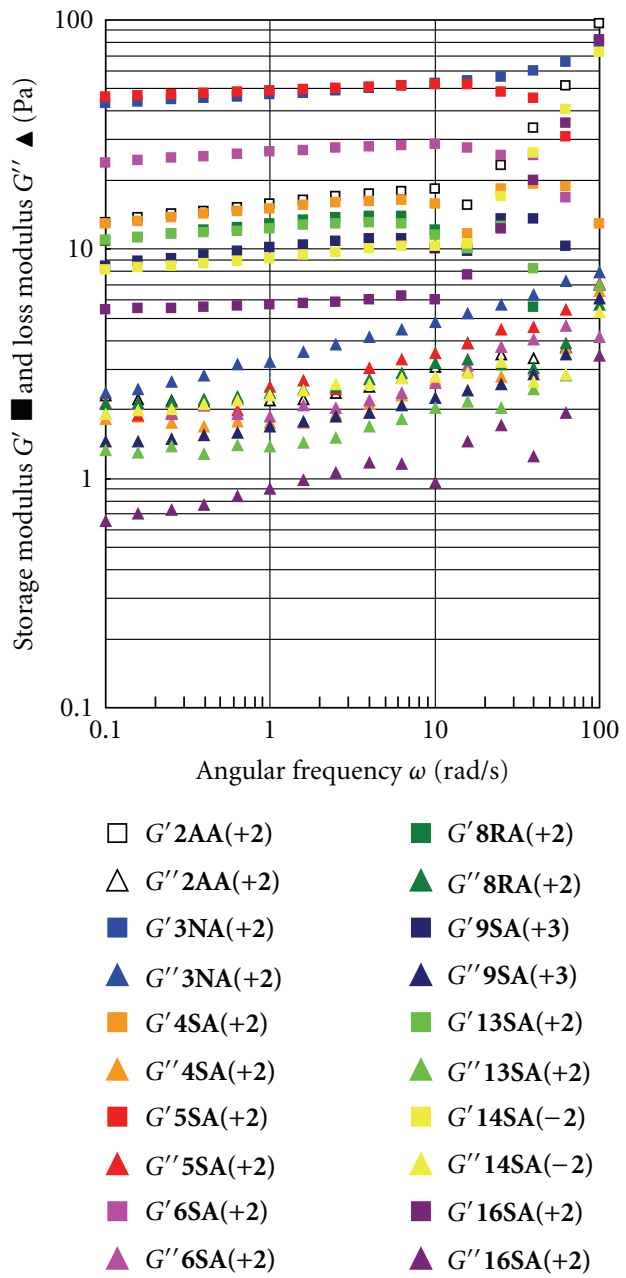

FIGURE 8: Dynamic viscoelasticity of peptide hydrogels. The storage modulus (squares) $G^{\prime}$ and loss modulus (triangles) $G^{\prime \prime}$ are plotted against the oscillatory frequency on log-log scales. The peptide concentration is $0.5 \mathrm{wt} / \mathrm{v} \%$ in $0.1 \mathrm{M}$ Tris- $\mathrm{HCl}$ buffer ( $\mathrm{pH} 7.5$ ).

The 16-residue peptide $4 \mathrm{SA}(+2)$ had higher $\beta$-sheet content than the 12-residue peptide $16 \mathrm{SA}(+2)$. This correlated with the number of hydrogen bonds and AABA lanes, which provide electrostatic attraction among molecules.

To evaluate the influence of hydrophobicity on the $\beta$ sheet content, $7 \mathrm{SL}(+2)$ was designed by replacing all the Ala residues of $4 \mathrm{SA}(+2)$ with highly hydrophobic leucine (Leu) residues. $7 \mathrm{SL}(+2)$ is not soluble in a neutral aqueous solution at a concentration of $0.5 \mathrm{wt} / \mathrm{v} \%$. Therefore, its solution for $\mathrm{CD}$ measurement was first prepared at an acidic $\mathrm{pH}$ and then adjusted to neutral. The $\beta$-sheet content of $7 \mathrm{SL}(+2)$ is slightly greater than that of $4 \mathrm{SA}(+2)$. Zhang reported that 8-residue peptide ELK8-II (LELELKLK) formed a $\beta$-sheet structure, although EAK8-II (AEAEAKAK) did not [47]. It seemed that the strong hydrophobicity of Leu residues led to an increase in the $\beta$-sheet content.

3.3. Observation of Nanofibers. The morphology of a peptide assembly on a mica substrate was observed by atomic force microscopy (AFM) (Figure 5). All the $\beta$-sheet structures 


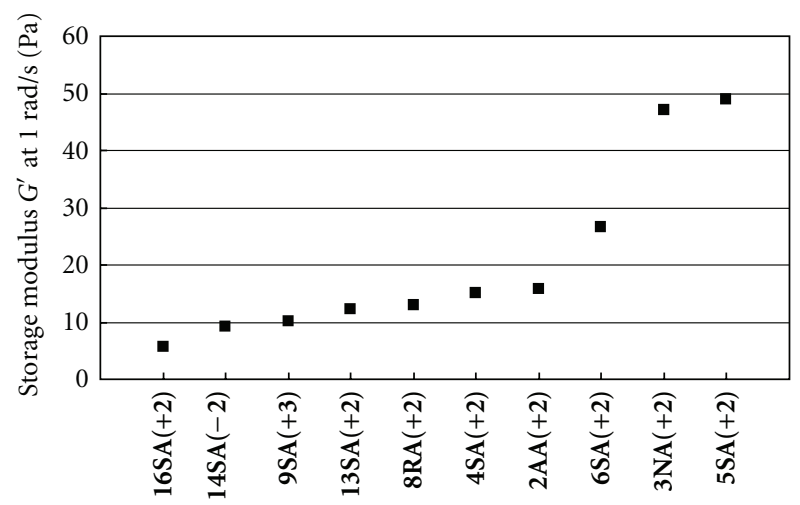

FIGURE 9: Rigidity of peptide hydrogels. The storage modulus $\mathrm{G}^{\prime}$ at $0.1 \mathrm{rad} / \mathrm{s}$ for peptides.

forming peptides self-assembled into nanofibers with a width of around $10 \mathrm{~nm}$. Considering that the radius curvature of the AFM tip is ca. $5 \mathrm{~nm}$, the nanofiber width corresponds to the molecular length of peptides.

The position and type of uncharged amino acid, type of basic amino acid, and degree of polymerization strongly influenced the nanofiber morphology.

Many nanofiber aggregates were observed for $1 \mathrm{SA}(+\mathbf{1})$, $10 \mathrm{SA}(-1)$, and $15 \mathrm{SA}(+1)$. These nanofibers were relatively short. This might be attributable to the electrostatic interaction among the nanofibers being too strong, that is, short nanofibers aggregated before the peptide molecules selfassembled to grow longer nanofibers.

Between 9SA(+3) and 12SA(-3), the latter, which assumed a random coil structure at neutral $\mathrm{pH}$, had fewer nanofibers. $\beta$-sheet formation is necessary to form a nanofiber.

8RA(+2) which has a net charge of +2 at neutral $\mathrm{pH}$ formed shorter nanofibers and many aggregates. It is considered that the electrostatic interaction among the nanofibers of $\mathbf{8 R A}(+2)$ is too strong to form long nanofiber because it has 6 AABA lanes. Apart from the net charge, the number of AABA lanes is also an important factor to be considered in order to avoid the aggregation of nanofibers.

Between $4 \mathrm{SA}(+2)$ and $7 \mathrm{SL}(+2)$, the latter, which is poorly soluble in an aqueous solution at neutral $\mathrm{pH}$, has shorter fibers. It is considered that $7 \mathrm{SL}(+2)$ aggregated before its nanofibers grew because of strong hydrophobic interaction.

3.4. Transparency of Peptide Gel. Aqueous solutions of each peptide $(0.5 \mathrm{wt} / \mathrm{v} \%)$ were prepared in $0.1 \mathrm{M}$ Tris- $\mathrm{HCl}$ buffer with a $\mathrm{pH}$ of around 7 (Figure 6). To examine the influence of differences in various characteristics of peptides on the transparency of the peptide solution, visible light spectroscopy was performed (Figure 7). Only peptides that formed a viscous solution were investigated. Aggregates, which scatter visible light, were responsible for decreasing the visible light transmittance in the solution. Therefore, it is considered that transparency strongly depends on the solubility of the peptide in the aqueous solution and the strength of the interaction among nanofibers.
Between 4SA(+2) and 9SA(+3), the latter has higher transparency. It is considered that a stronger electrostatic repulsive force acts among the nanofibers of $9 \mathrm{SA}(+3)$ than among those of $4 \mathrm{SA}(+2)$, because the net charge of the former is greater than that of the latter. This inhibited aggregate formation and led to the higher transparency of 9SA $(+3)$.

Once 8RA(+2) solution was stirred using a vortex mixer, its transparency decreased and the peptide was precipitated. It is considered that the electrostatic attraction among the nanofibers of $\mathbf{8 R A}(+2)$ is too strong. This caused aggregation of the $8 \mathrm{RA}(+2)$ nanofibers. However, $\mathbf{8 R A}(+2)$ has better solubility compared with $1 \mathrm{SA}(+1)$ and $10 \mathrm{SA}(-1)$ that have $6 \mathrm{AABA}$ lanes. It is obvious that the net charge influences the solubility of the peptide. Aggeli et al. reported that at least one additional charged amino acid per molecule stabilizes nanofibers against aggregation [34].

Among $4 \mathrm{SA}(+2)$, $5 \mathrm{SA}(+2)$, and $6 \mathrm{SA}(+2)$, the order of transparency is as follows: $4 \mathrm{SA}(+2)>5 \mathrm{SA}(+2)>6 \mathrm{SA}(+2)$. $6 \mathrm{SA}(+2)$ tends to aggregate the most. It may be difficult for 6SA(+2) nanofibers to form cross-linkages via electrostatic interaction because their AABA lane is located at the side of the nanofibers. If the nanofibers do not form a 3D network, they may entangle and lead to aggregation.

Among $2 \mathrm{AA}(+2), 3 \mathrm{NA}(+2)$, and $4 \mathrm{SA}(+2)$, the order of transparency is as follows: $4 \mathrm{SA}(+2)>2 \mathrm{AA}(+2)>3 \mathrm{NA}(+2)$. The transparency of $3 \mathrm{NA}(+2)$ containing hydrophilic Asn residue is lower than that of $2 \mathrm{AA}(+2)$ containing hydrophobic Ala residue. This means that $3 \mathrm{NA}(+2)$ tends to aggregate more than $2 \mathrm{AA}(+2)$. This may be related to hydrogen bonds and side-chain size. Hydrogen bonds among nanofibers may accelerate aggregation. As Zhang pointed out [48, 49], structural compatibility may affect both nanofiber and hydrogel formation because an Asn residue is similar in size to an Asp residue.

The transparency of the 12 -residue peptide $16 \mathrm{SA}(+2)$ is higher than that of the 16 -residue peptide $4 \mathrm{SA}(+2)$. This is because the electrostatic interaction among nanofibers of the former, which has fewer AABA lines, is weaker than that among nanofibers of the latter.

3.5. Dynamic Viscoelasticity of Peptide Gel. The viscoelasticity of the peptide solution was investigated using a rotational rheometer (Figure 8 and Supporting Information Figure S2, see Figure S2 in Supplementary Material available online at doi:10.1155/2012/537262). Only those peptides that formed viscous solutions were investigated. The values of the storage modulus $\mathrm{G}^{\prime}$ and loss modulus $\mathrm{G}^{\prime \prime}$ at $1 \mathrm{rad} / \mathrm{s}$ for each solution are summarized in Figure 9. For gels, $G^{\prime}$ and $G^{\prime \prime}$ are relatively constant with the oscillatory frequency, and $G^{\prime}$ is much greater than zero $[37,50]$. Figure 9 indicates that all the tested peptides formed gels.

Between 4SA(+2) and 9SA(+3), the former has a higher $\mathrm{G}^{\prime}$ value. It is considered that a stronger electrostatic repulsive force acts among $9 \mathrm{SA}(+3)$ nanofibers than among $4 \mathrm{SA}(+2)$ nanofibers because of their net charges. Therefore, weaker electrostatic attraction at the cross-linking points of $9 \mathrm{SA}(+3)$ provides a lower $\mathrm{G}^{\prime}$ value than that of $4 \mathrm{SA}(+2)$. 


\begin{tabular}{|c|c|c|}
\hline \multicolumn{3}{|r|}{16 residues } \\
\hline \multicolumn{3}{|r|}{$\mathrm{R}(+), \mathrm{D}(-)$} \\
\hline Peptide & Net charge $(\mathrm{pH} 7)$ & Amino acid sequence \\
\hline RADA16 & 0 & $\mathrm{CH}_{3} \mathrm{CO}-\mathrm{RADARADARADARADA}-\mathrm{NH}_{2}$ \\
\hline $1 \mathrm{SA}(+1)$ & +1 & $\mathrm{CH}_{3} \mathrm{CO}$-RASARADARADARADA-NH ${ }_{2}$ \\
\hline $2 \mathrm{AA}(+2)$ & +2 & $\mathrm{CH}_{3} \mathrm{CO}-\mathrm{RAAA}$ RADARAAA RADA-NH${ }_{2}$ \\
\hline $3 \mathrm{NA}(+2)$ & +2 & $\mathrm{CH}_{3} \mathrm{CO}-\mathrm{RANARADARANARADA}-\mathrm{NH}_{2}$ \\
\hline $4 \mathrm{SA}(+2)$ & +2 & $\mathrm{CH}_{3} \mathrm{CO}-\mathrm{RASARADARASARADA}-\mathrm{NH}_{2}$ \\
\hline $5 S A(+2)$ & +2 & $\mathrm{CH}_{3} \mathrm{CO}-\mathrm{RASARADARADARASA}-\mathrm{NH}_{2}$ \\
\hline $6 \mathrm{SA}(+2)$ & +2 & $\mathrm{CH}_{3} \mathrm{CO}-\mathrm{RADARASARASARADA}-\mathrm{NH}_{2}$ \\
\hline $7 \mathrm{SL}(+2)$ & +2 & $\mathrm{CH}_{3} \mathrm{CO}-\mathrm{RLSLRLDLRLSLRLDL-NH_{2 }}$ \\
\hline $8 \mathrm{RA}(+2)$ & +2 & $\mathrm{CH}_{3} \mathrm{CO}-\mathrm{RARARADARADARADA}-\mathrm{NH}_{2}$ \\
\hline $9 \mathrm{SA}(+3)$ & +3 & $\mathrm{CH}_{3} \mathrm{CO}-\mathrm{RASARASARASARADA}-\mathrm{NH}_{2}$ \\
\hline 10SA $(-1)$ & -1 & $\mathrm{CH}_{3} \mathrm{CO}-\mathrm{RADARADARADASADA}-\mathrm{NH}_{2}$ \\
\hline $11 S A(-2)$ & -2 & $\mathrm{CH}_{3} \mathrm{CO}-\mathrm{SADARADASADARADA}-\mathrm{NH}_{2}$ \\
\hline $12 \mathrm{SA}(-3)$ & -3 & $\mathrm{CH}_{3} \mathrm{CO}-\mathrm{RADASADASADASADA}-\mathrm{NH}_{2}$ \\
\hline \multicolumn{3}{|r|}{16 residues } \\
\hline \multicolumn{3}{|r|}{$\mathrm{K}(+), \mathrm{E}(-)$} \\
\hline $13 S A(+2)$ & +2 & $\mathrm{CH}_{3} \mathrm{CO}-\mathrm{KASAKAEAKASAKAEA-NH_{2 }}$ \\
\hline $14 \mathrm{SA}(-2)$ & -2 & $\mathrm{CH}_{3} \mathrm{CO}$-SAEAKAEASAEAKAEA-NH ${ }_{2}$ \\
\hline \multicolumn{3}{|r|}{12 residues } \\
\hline \multicolumn{3}{|r|}{$\mathrm{R}(+), \mathrm{D}(-)$} \\
\hline $15 \mathrm{SA}(+1)$ & +1 & $\mathrm{CH}_{3} \mathrm{CO}-\mathrm{RASARADARADA}-\mathrm{NH}_{2}$ \\
\hline $16 \mathrm{SA}(+2)$ & +2 & $\mathrm{CH}_{3} \mathrm{CO}-\mathrm{RASARADARASA}-\mathrm{NH}_{2}$ \\
\hline
\end{tabular}

FIgURE 10: List of peptides.

8RA(+2) formed a hydrogel in $0.1 \mathrm{M}$ Tris- $\mathrm{HCl}$ aqueous solution. However, when the solution was stirred using a vortex mixer, its viscosity decreased. Therefore, the solution was placed on the rheometer immediately after being sonicated using a homogenizer. $8 \mathrm{RA}(+2)$ showed a relatively low $\mathrm{G}^{\prime}$ value. This suggested that the nanofibers of $\mathbf{8 R A}(+2)$ aggregated and did not form a homogenous 3D network. This correlated with the AFM observations.

The viscoelasticity varied according to the position of the AABA lane. Among 4SA(+2), 5SA(+2), and $6 \mathrm{SA}(+2)$, $5 \mathrm{SA}(+2)$, which has AABA lanes at the center of the nanofibers, showed the highest $G^{\prime}$ value. This correlated with its $\beta$-sheet structure content. $6 \mathrm{SA}(+2)$ tends to aggregate, and it is considered that the $G^{\prime}$ value of its solution reflected the rigidity of its aggregated particles.

$3 \mathrm{NA}(+2)$ showed a higher $\mathrm{G}^{\prime}$ value than $\operatorname{did} 2 \mathrm{AA}(+2)$ and 4SA(+2). This correlated with its $\beta$-sheet structure content. It seemed that the hydrogen bond among the $-\mathrm{CONH}_{2}$ group of Asn residues and the Arg residues on nanofibers strengthened the physical cross-linkage among nanofibers.

The $\mathrm{G}^{\prime}$ value of the 16 -residue peptide $4 \mathrm{SA}(+2)$ is higher than that of the 12 -residue peptide $16 \mathrm{SA}(+2)$. This correlated with their $\beta$-sheet structure content. This is related to the observation that the electrostatic interaction among 4SA $(+2)$ nanofibers is stronger than that among $16 \mathrm{SA}(+2)$ nanofibers because the former has more AABA lanes.
Both 4SA(+2) with Arg/Asp amino acids and 13SA(+2) with Lys/Glu amino acids showed similar viscoelastic property profiles. On the other hand, between 11SA(-2) with Arg/Asp amino acids and $14 \mathrm{SA}(-2)$ with Lys/Glu amino acids, stirring the former using a vortex mixer made the solution opaque, although this did not occur with the latter. 11SA $(-2)$ did not form a transparent hydrogel, although it formed nanofibers. It may be difficult for 11SA(-2) nanofibers to form cross-linkages via electrostatic interaction. Molecular models in Figure 1 may help us understand these differences. Zhang pointed out that structurally compatible constituents were key factors for molecular self-assembly [48, 49]. 4SA(+2) and 13SA(+2) have similar molecular structure. On the other hand, 11SA(-2) forms bigger bulges on a nanofiber surface comparing with 14SA(-2). A difference between the side chain lengths of positively and negatively charged amino acid residues might affect the interaction among nanofibers. Negatively charged peptides formed a transparent nanofiber hydrogel via the arrangement of appropriate types of charged amino acids. This might be related to the molecular structure of the peptide, although this has not yet been determined. Further research on negatively charged peptides containing a combination of Arg and Glu as well as Lys and Asp is necessary to determine the parameters necessary for forming a hydrogel. 


\section{Conclusions}

We conducted a detailed investigation of the parameters necessary for preparing transparent nanofiber hydrogels at neutral $\mathrm{pH}$. At least two additional charged amino acids (per peptide) are necessary to form such hydrogels. When designing an amino acid sequence, it is important to consider the net charge and position of the charged amino acids, and to not allow basic amino acids to face other basic ones in the antiparallel $\beta$-sheet structure.

$\mathrm{CD}$ measurement indicated that the $\beta$-sheet content was high when the AABA lanes were located at the center of the nanofiber. According to the AFM observation, all peptides except 12SA $(-3)$ formed nanofibers at neutral $\mathrm{pH}$, although there were differences in the nanofiber lengths. A peptide with a net charge of +1 or -1 and highly hydrophobic amino acids formed short nanofibers or it aggregated. RA(+2), which has 6 AABA lanes on a nanofiber, formed short nanofibers and their aggregates, although it has +2 net charge. Considering that it did not form a transparent hydrogel, adding additional charged amino acids is not sufficient to form a transparent nanofiber hydrogel. Visible light spectroscopy revealed that peptides with a higher net charge formed a more transparent gel. Using a large amount of Leu residue, which has high hydrophobicity, decreases the solubility of the peptide, although it serves to increase the $\beta$-sheet content. A rheometric assay showed that a 16residue peptide with AABA lanes located at the center of its nanofibers had the highest storage modulus. Hydrogen bonding among nanofibers served to increase the mechanical strength of the hydrogels. These results can serve as useful guidelines for designing peptides to form a transparent nanofiber hydrogel.

The properties of self-assembling peptide hydrogels can be controlled by arranging the amino acids appropriately. Because a charged amino acid can be placed precisely on nanofibers, the interaction among nanofibers and chemicals or cells can be controlled more precisely than that among conventional nanofibers. Thus, the peptide library created in this study may be useful for preparing 3D cell culture scaffolds and DDS devices.

\section{Acknowledgments}

The authors thank Mr. Makoto Hattori and Mr. Yuya Ishida of the Nagoya Institute of Technology for their technical support for peptide synthesis. They are grateful to Dr. Yasuyuki Ishida of Chubu University for generously allowing the use of a MALDI-TOF mass spectrometer.

\section{References}

[1] J. Aizenberg, A. J. Black, and G. M. Whitesides, "Control of crystal nucleation by patterned self-assembled monolayers," Nature, vol. 398, no. 6727, pp. 495-498, 1999.

[2] T. Kunitake and Y. Okahata, "A totally synthetic bilayer membrane," Journal of the American Chemical Society, vol. 99, no. 11, pp. 3860-3861, 1977.
[3] S. I. Kawano, N. Fujita, and S. Shinkai, "Novel hostguest organogels as stabilized by the formation of crownammonium pseudo-rotaxane complexes," Chemical Communications, vol. 9, no. 12, pp. 1352-1353, 2003.

[4] N. Mizoshita, K. Hanabitsa, and T. Kato, "Self-aggregation of an aniino acid derivative as a route to liquid-crystalline physical gels-faster response to electric fields," Advanced Materials, vol. 11, no. 5, pp. 392-394, 1999.

[5] M. Suzuki, M. Yumoto, M. Kimura, H. Shirai, and K. Hanabusa, "Novel family of low molecular weight hydrogelators based on L-lysine derivatives," Chemical Communications (cambridge, England), vol. 8, pp. 884-885, 2002.

[6] S. Kiyonaka, K. Sugiyasu, S. Shinkai, and I. Hamachi, "First thermally responsive supramolecular polymer based on glycosylated amino acid," Journal of the American Chemical Society, vol. 124, no. 37, pp. 10954-10955, 2002.

[7] S. Kiyonaka, K. Sada, I. Yoshimura, S. Shinkai, N. Kato, and I. Hamachi, "Semi-wet peptide/protein array using supramolecular hydrogel," Nature Materials, vol. 3, no. 1, pp. 58-64, 2004.

[8] W.-S. Li, W.-D. Jang, and T. Aida, "Molecular design and self-assembly of functional dendrimers," in Macromolecular Engineering: Precise Synthesis, Materials Properties, Applications, K. Matyjaszewski, Y. Gnanou, and L. Leibler, Eds., vol. 2, pp. 1057-1102, Wiley-VCH Verlag GmbH \& Co. KGaA, Weinheim, Germany, 2007.

[9] W. Zhang, W. Jin, T. Fukushima, A. Saeki, S. Seki, and T. Aida, "Supramolecular linear heterojunction composed of graphitelike semiconducting nanotubular segments," Science, vol. 334, no. 6054, pp. 340-343, 2011.

[10] T. Shimizu, M. Kogiso, and M. Masuda, "Vesicle assembly in microtubes," Nature, vol. 383, no. 6600, pp. 487-488, 1996.

[11] R. B. Merrifield, "Solid phase peptide synthesis. i. the synthesis of a tetrapeptide," Journal of the American Chemical Society, vol. 85, no. 14, pp. 2149-2154, 1963.

[12] A. Aggeli, M. Bell, N. Boden et al., "Responsive gels formed by the spontaneous self-assembly of peptides into polymeric $\beta$-sheet tapes," Nature, vol. 386, no. 6622, pp. 259-262, 1997.

[13] H. Mihara and Y. Takahashi, "Engineering peptides and proteins that undergo $\alpha$-to- $\beta$ transitions," Current Opinion in Structural Biology, vol. 7, no. 4, pp. 501-508, 1997.

[14] H. A. Lashuel, S. R. LaBrenz, L. Woo, L. C. Serpell, and J. W. Kelly, "Protofilaments, filaments, ribbons, and fibrils from peptidomimetic self-assembly: implications for amyloid fibril formation and materials science," Journal of the American Chemical Society, vol. 122, no. 22, pp. 5262-5277, 2000.

[15] J. D. Hartgerink, E. Beniash, and S. I. Stupp, "Self-assembly and mineralization of peptide-amphiphile nanofibers," Science, vol. 294, no. 5547, pp. 1684-1688, 2001.

[16] J. P. Schneider, D. J. Pochan, B. Ozbas, K. Rajagopal, L. Pakstis, and J. Kretsinger, "Responsive hydrogels from the intramolecular folding and self-assembly of a designed peptide," Journal of the American Chemical Society, vol. 124, no. 50, pp. 1503015037, 2002.

[17] M. G. Ryadnov and D. N. Woolfson, "Introducing branches into a self-assembling peptide fiber," Angewandte Chemie International Edition, vol. 42, no. 26, pp. 3021-3023, 2003.

[18] M. Reches and E. Gazit, "Casting metal nanowires within discrete self-assembled peptide nanotubes," Science, vol. 300, no. 5619, pp. 625-627, 2003.

[19] T. Koga, M. Matsuoka, and N. Higashi, "Structural control of self-assembled nanofibers by artificial $\beta$-sheet peptides composed of D- or L-isomer," Journal of the American Chemical Society, vol. 127, no. 50, pp. 17596-17597, 2005. 
[20] V. Jayawarna, A. Smith, J. E. Gough, and R. V. Ulijn, "Threedimensional cell culture of chondrocytes on modified diphenylalanine scaffolds," Biochemical Society Transactions, vol. 35, no. 3, pp. 535-537, 2007.

[21] K. Murasato, K. Matsuura, and N. Kimizuka, "Self-assembly of nanofiber with uniform width from wheel-type trigonal- $\beta$ sheet-forming peptide," Biomacromolecules, vol. 9, no. 3, pp. 913-918, 2008.

[22] E. L. Bakota, Y. Wang, F. R. Danesh, and J. D. Hartgerink, "Injectable multidomain peptide nanofiber hydrogel as a delivery agent for stem cell secretome," Biomacromolecules, vol. 12, no. 5, pp. 1651-1657, 2011.

[23] C. J. Bowerman, W. Liyanage, A. J. Federation, and B. L. Nilsson, "Tuning $\beta$-sheet peptide self-assembly and hydrogelation behavior by modification of sequence hydrophobicity and aromaticity," Biomacromolecules, vol. 12, no. 7, pp. 2735-2745, 2011.

[24] S. Zhang, T. Holmes, C. Lockshin, and A. Rich, "Spontaneous assembly of a self-complementary oligopeptide to form a stable macroscopic membrane," Proceedings of the National Academy of Sciences of the United States of America, vol. 90, no. 8, pp. 3334-3338, 1993.

[25] S. Zhang, C. Lockshin, A. Herbert, E. Winter, and A. Rich, "Zuotin, a putative $\mathrm{z}$-dna binding protein in saccharomyces cerevisiae," The EMBO Journal, vol. 11, no. 10, pp. 3787-3796, 1992.

[26] H. Yokoi, T. Kinoshita, and S. Zhang, "Dynamic reassembly of peptide rada16 nanofiber scaffold," Proceedings of the National Academy of Sciences of the United States of America, vol. 102, no. 24, pp. 8414-8419, 2005.

[27] Y. Nagai, L. D. Unsworth, S. Koutsopoulos, and S. Zhang, "Slow release of molecules in self-assembling peptide nanofiber scaffold," Journal of Controlled Release, vol. 115, no. 1, pp. 18-25, 2006.

[28] S. Koutsopouios, L. D. Unsworth, Y. Nagai, and S. Zhang, "Controlled release of functional proteins through designer self-assembling peptide nanofiber hydrogel scaffold," Proceedings of the National Academy of Sciences of the United States of America, vol. 106, no. 12, pp. 4623-4628, 2009.

[29] R. G. Ellis-Behnke, Y. X. Liang, D. K. C. Tay et al., "Nano hemostat solution: immediate hemostasis at the nanoscale," Nanomedicine: Nanotechnology, Biology, and Medicine, vol. 2, no. 4, pp. 207-215, 2006.

[30] S. Zhang, T. C. Holmes, C. M. DiPersio, R. O. Hynes, X. $\mathrm{Su}$, and A. Rich, "Self-complementary oligopeptide matrices support mammalian cell attachment," Biomaterials, vol. 16, no. 18 , pp. 1385-1393, 1995.

[31] R. G. Ellis-Behnke, Y. X. Liang, S. W. You et al., "Nano neuro knitting: peptide nanofiber scaffold for brain repair and axon regeneration with functional return of vision," Proceedings of the National Academy of Sciences of the United States of America, vol. 103, no. 13, pp. 5054-5059, 2006.

[32] K. Wang, J. D. Keasling, and S. J. Muller, "Effects of the sequence and size of non-polar residues on self-assembly of amphiphilic peptides," International Journal of Biological Macromolecules, vol. 36, no. 4, pp. 232-240, 2005.

[33] M. R. Caplan, E. M. Schwartzfarb, S. Zhang, R. D. Kamm, and D. A. Lauffenburger, "Control of self-assembling oligopeptide matrix formation through systematic variation of amino acid sequence," Biomaterials, vol. 23, no. 1, pp. 219-227, 2002.

[34] A. Aggeli, M. Bell, N. Boden, L. M. Carrick, and A. E. Strong, "Self-assembling peptide polyelectrolyte $\beta$-sheet complexes form nematic hydrogels," Angewandte Chemie, vol. 42, no. 45, pp. 5603-5606, 2003.
[35] Y. Takahashi, A. Ueno, and H. Mihara, "Amyloid architecture: complementary assembly of hetero-geneous combinations of three or four peptides into amyloid fibrils," European Journal of Chemical Biology, vol. 3, no. 7, pp. 637-642, 2002.

[36] J. H. Collier, B. H. Hu, J. W. Ruberti et al., "Thermally and photochemically triggered self-assembly of peptide hydrogels," Journal of the American Chemical Society, vol. 123, no. 38, pp. 9463-9464, 2001.

[37] M. R. Caplan, P. N. Moore, S. Zhang, R. D. Kamm, and D. A. Lauffenburger, "Self-assembly of a $\beta$-sheet protein governed by relief of electrostatic repulsion relative to van der waals attraction," Biomacromolecules, vol. 1, no. 4, pp. 627-631, 2000.

[38] J. K. Kretsinger, L. A. Haines, B. Ozbas, D. J. Pochan, and J. P. Schneider, "Cytocompatibility of self-assembled $\beta$-hairpin peptide hydrogel surfaces," Biomaterials, vol. 26, no. 25, pp. 5177-5186, 2005.

[39] H. Yokoi and T. Kinoshita, "Design of self-assembling peptides to form transparent gels at neutral pH," Peptide Science, vol. 2007, pp. 109-110, 2008.

[40] Y. Zhao, H. Yokoi, M. Tanaka, T. Kinoshita, and T. Tan, "Selfassembled ph-responsive hydrogels composed of the ratea16 peptide," Biomacromolecules, vol. 9, no. 6, pp. 1511-1518, 2008.

[41] A. Nagayasu, H. Yokoi, J.A. Minaguchi, Y.Z. Hosaka, H. Ueda, and K. Takehana, "Efficacy of self-assembled hydrogels composed of positively or negatively charged peptides as scaffolds for cell culture," Journal of Biomaterials Applications, vol. 26, no. 6, pp. 651-665, 2012.

[42] Y. Nagai, H. Yokoi, K. Kaihara, and K. Naruse, "The mechanical stimulation of cells in 3D culture within a self-assembling peptide hydrogel," Biomaterials, vol. 33, no. 4, pp. 1044-1051, 2012.

[43] N.K. White, "Biomer," http://www.netsci.org/Resources/Softw are/Modeling/MMMD/.

[44] W. Humphrey, A. Dalke, and K. Schulten, "Vmd: visual molecular dynamics," Journal of Molecular Graphics, vol. 14, no. 1, pp. 33-38, 1996.

[45] G. D. Fasman, P. Y. Chou, and A. J. Adler, "Prediction of the conformation of the histones," Biophysical Journal, vol. 16, no. 10, pp. 1201-1238, 1976.

[46] N. Greenfield and G. D. Fasman, "Computed circular dichroism spectra for the evaluation of protein conformation," Biochemistry, vol. 8, no. 10, pp. 4108-4116, 1969.

[47] S. Zhang, "Emerging biological materials through molecular self-assembly," Biotechnology Advances, vol. 20, no. 5-6, pp. 321-339, 2002.

[48] S. Zhang, C. Lockshin, A. Rich, and T. Holmes, "Stable macroscopic membranes formed by self-assembly of amphiphilic peptides and uses therefor," US Patent 5670483, 1997.

[49] S. Zhang, "Molecular self-assembly," in Encyclopedia of Materials: Science \& Technology, pp. 5822-5829, Elsevier Science, Oxford, UK, 2001.

[50] A. H. Clark and S. B. Ross-Murphy, "Structural and mechanical properties of biopolymer gels," Advances in Polymer Science, Biopolymers, vol. 83, pp. 57-192, 1987. 

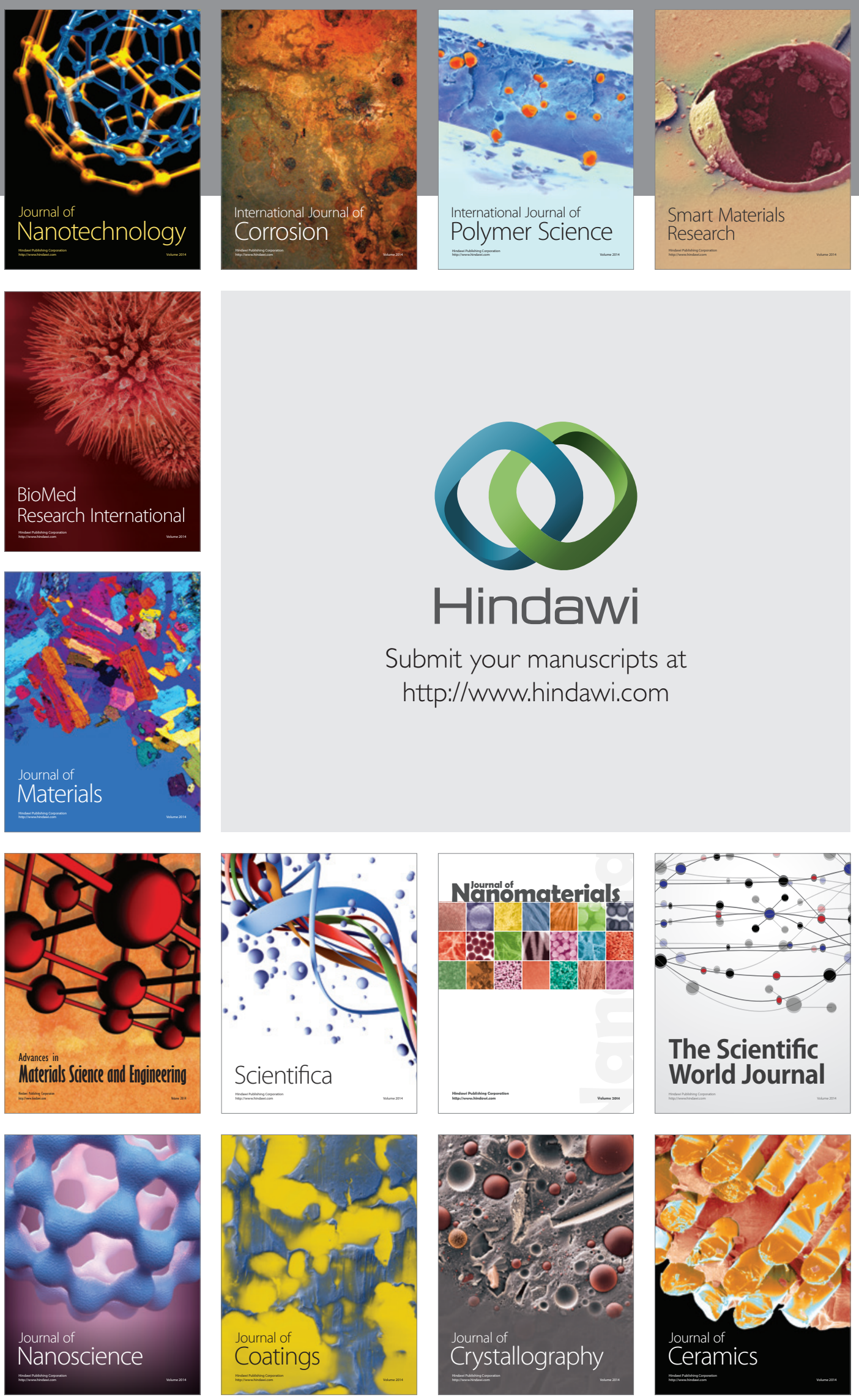

The Scientific World Journal

Submit your manuscripts at

http://www.hindawi.com

\section{World Journal}

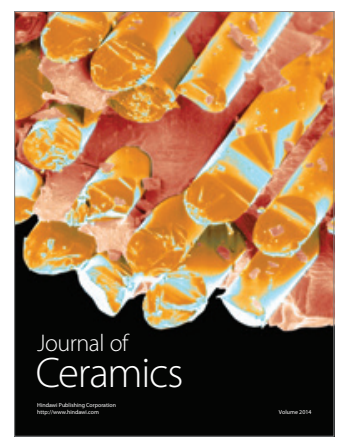

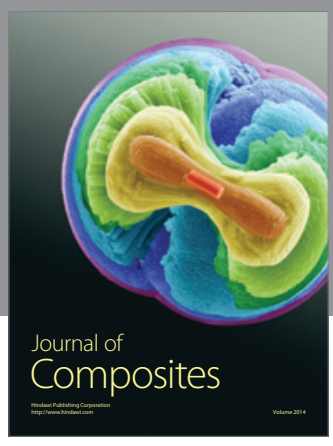
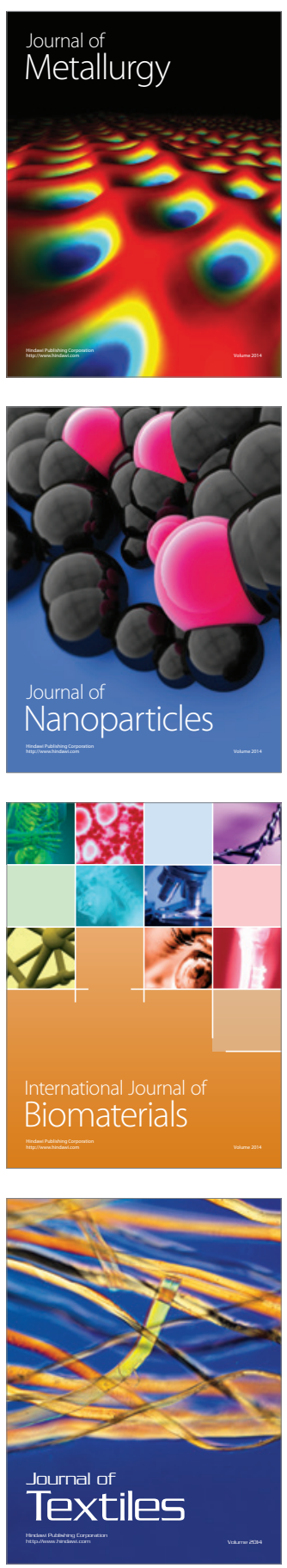